\title{
500 Years Standing Up: Earthquakes from the Michelangelo's David Ankles Perspective
}

\author{
${ }^{1}$ Dipartimento Scienze della Terra, Università di Firenze, Italy \\ ${ }^{2}$ Centro di Servizi di Microscopia Elettronica e Microanalisi (M.E.M.A), Università di Firenze, Italy \\ ${ }^{3}$ Quantech Systems, USA \\ *Corresponding author: Rimondi V, Dipartimento Scienze della Terra, Università di Firenze, Firenze, Italy
}

Costagliola $\mathrm{P}^{1}$, Marchetti $\mathrm{E}^{1}$, Rimondi $\mathrm{V}^{1 *}$, Benvenuti $\mathrm{M}^{1}$, Chiarantini $\mathrm{L}^{2}$, Parrini $\mathrm{P}^{1}$, Pecchioni $\mathrm{E}^{1}$ and Yaghoubian $\mathrm{J}^{3}$

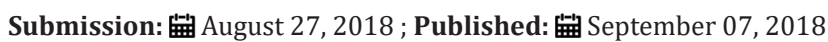

\begin{abstract}
Earthquakes could distress the long-term stability and preservation of the David marble statue of Michelangelo Buonarroti, a universally recognized masterpiece of the Italian Renaissance, presently exhibited in Galleria dell' Accademia (Firenze, Italy). Small-scale tests indicated that the multiple hairline cracks of unknown origin located at the David's ankles are likely weak point of the statue. In 1994, a full-size David marble replica located at Glendale (CA, USA) broke along ankles cracks caused by the Northridge (CA) earthquake. Although both statues were carved from the Apuane Alps (Italy), petrographic fabric of the original David and the replica marbles are rather different. Investigation of historical earthquake and available seismic data at Firenze showed a 500 year-recurrence time of ground acceleration values comparable to that of the Glendale event. Therefore, there is a small, but finite, seismic risk for the David statue in its present location, suggesting the opportunity of appropriate protection measures.
\end{abstract}

Keywords: Firenze; Michelangelo's david; Marble; Preservation; Earthquake

\section{Introduction}

Presently exhibited at the Galleria dell' Accademia of Firenze (central Italy), the David marble statue (1501-1504) of Michelangelo Buonarroti is universally known as one of the most important symbols of Italian Renaissance [1]. The statue's left leg and the so called "tree trunk" [1], positioned beside the right leg ankle, substantially support most of statue's vertical and horizontal applied loads. There are visible horizontal hairlines on the trunk and the left ankle, the origin and source of which are not yet clear. Anderson [2] affirmed that cracks were already present in the original marble block from which the statue was carved. However, cracks could have been induced also during relocation of the statue to the Galleria dell' Accademia in 1873 and/or during restoration and tilting [3]. Recently, the effect of visitor's footfall vibrations (more than 1 million people visited the Accademia each year) on the statue stability was moreover investigated [4].

The recent earthquakes in central Italy (August 2016-January 2017) caused major concern about the David's preservation due to the weakened state of the legs and ankles - the blind spot of the statue's stability $[3,5,6]$. In 1994, an earthquake centered in Northridge (CA, USA) shook the Forest Lawn Memorial Park in vicinity of the city of Glendale, where there was placed a full-size David replica statue, carved from a Carrara (Apuane Alps, Tuscany, Italy) marble block, i.e. the same marble provenance for the original David statue. To strengthen the left foot of the statue, a stainlesssteel pin was inserted in the left ankle of the Glendale replica, most likely after carving [7]. Despite this support, the reversal stresses originated by the Northridge earthquake damaged the replica David's statue [7]. The collapse of the statue was driven by stresses induced by ground shaking that caused fractures at the left ankle and right knee, closely resembling those observed in a small-scale David centrifugal test [3] (Figure 1).

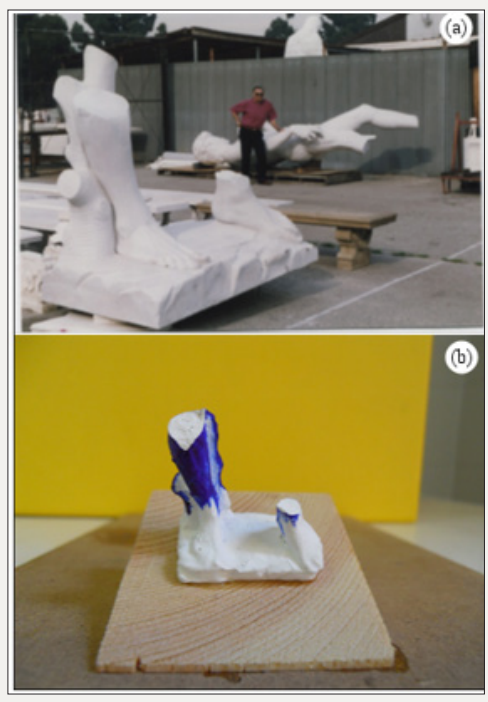

Figure 1: a) The Glendale David after the Northridge earthquake.

b) the David replica crushed in the Corti et al. [3] experiment. 
The objective of this paper is to evaluate the long-term stability and preservation of the Michelangelo's David due to the possible occurrence of a seismic event in the city of Firenze. In particular, we investigated whether the seismicity of Firenze could produce ground accelerations similar to those measured during the Northridge shake event. For a comparison with the Northridge event, we examined the historical seismicity records of the city of Firenze to estimate maximum ground acceleration compatible with the local geological features. Moreover, the mechanical and petro-graphical marble characteristics of the two statues, i.e. the real Michelangelo's and Glendale replica, were also examined and compared.

\section{Methods}

The Glendale David statue was investigated for mineralogical, petrographic and mechanical (resistance to compression) characteristics in order to be compared with those of the real Michelangelo's David [1]. The mineralogical and textural features of the Glendale David were examined by picking a small fragment of marble from the statue basement. For mineralogy, XRD diffraction spectra were obtained using a Philips PW 1050/37 diffractometer equipped with a $\mathrm{Cu} \mathrm{X}$-ray tube hold at the Dipartimento di Scienze della Terra of Firenze. Operating set-up was a step-scanning range from 5 to $70^{\circ} 2 \theta$ at angular increments of $0.01^{\circ}$. Polished thin sections $(30 \mu \mathrm{m})$ allowed in addition the characterization of petrographic features in transmitted light microscopy. For compression test, two core samples $(2.5$ in diameter $\times 7.5 \mathrm{~cm}$ in length) were extracted from the bottom of the base of the Glendale replica in a direction perpendicular to the base. Samples were tested for compressive strength test by Quantech Systems, California, USA.

\section{Results and Discussion}

\section{The Northridge earthquake}

On 17 th January 1994, the Northridge earthquake (momentum magnitude, Mw=6.7) struck Southern California and produced extensive damage to large communities in the Los Angeles basin [8]. The earthquake was probably caused by a thrust fault located at a distance of about $30 \mathrm{~km}$ west-northwest of downtown Los Angeles having a plane strike of $\mathrm{N} 79^{\circ} \mathrm{W}$ and dipping $35-45^{\circ}$ southwest; the focal depth was at about $19 \mathrm{~km}$ [9]. The Northridge earthquake was recorded with a dense network of seismic stations at epicentral distances ranging between 2 and $300 \mathrm{~km}$ and produced peak horizontal acceleration spanning from maximum values of $\sim 1.82 \mathrm{~g}$ for stations within $10 \mathrm{~km}$ from epicenter, down to $0.01 \mathrm{~g}$ at distances exceeding $100 \mathrm{~km}$ [9]. More than 200 free-field records showed accelerations exceeding $0.01 \mathrm{~g}$. The maximum effects were observed to the north-west of the earthquake epicenter, possibly affected by event directivity [8] as well as by amplification effects because of soft soils and topography [9].

The exact peak ground acceleration produced by the event in the Forest Lawn Memorial Park in Glendale, located approximately $30 \mathrm{~km}$ east from the earthquake epicenter, is not known. However, the closest records are available from stations placed some km south of Burbank (approximately 4km northward from the Memorial Park, about $22 \mathrm{~km}$ east of the epicenter) where an horizontal acceleration between 0.25 and $0.3 \mathrm{~g}$ was recorded [10]. Therefore, lacking additional information on possible local site effects produced by the subsurface, we assumed this value $(0.25-0.3 \mathrm{~g})$ as the ground acceleration experienced at the Forest Lawn Memorial Park where the David replica was placed. This assumption is in good agreement with the shake maps at the Forest Lawn Memorial Park provided by USGS for the event.

\section{Earthquakes in Firenze}

The city of Firenze is located in a fluvio-lacustrine basin. The main active faults are located

A. $\sim 20-30 \mathrm{~km}$ to the north (Mugello Basin), potentially able to cause an earthquake with Mw as high as $\sim 6.4$.

B. $\quad \sim 10-20 \mathrm{~km}$ to the south (Chianti), where a maximum predictable magnitude is about $\mathrm{Mw}=5.5$ [11].

Historically, the city was affected by several earthquakes with magnitude larger than $\mathrm{Mw}=4$. The strongest event was the 1919 earthquake having an epicenter in the Mugello Basin, with a magnitude of $M w=6.38$ [11]. The worst damages in Firenze occurred, however, during the 1895 event that had a Mw=5.5 (estimated from macroseismic observations), but with a smaller epicentral distance $(\sim 10 \mathrm{~km})$.

Since 2004, a probabilistic assessment of seismic hazard in Italy is available in terms of horizontal Peak Ground Acceleration (PGA) measured in hard ground [12] with $10 \%$ probability of exceedance in 50 years. This information allows evaluating the maximum horizontal ground acceleration expected every 475 years. This time span is currently used to regulate the best practices for building construction adopted in the country. The evaluated PGA results from a seismic source model for the Italian territory [13] and attenuation laws evaluated experimentally for the country [14]. Given the mean distance to the closest seismogenic zone, and expected magnitudes, a possible value for the horizontal peak ground acceleration for the city of Firenze should be in the order of $0.125-0.15 \mathrm{~g}$. This range is considered to be valid for bedrock; possible local site effects are not considered in the peak ground acceleration computation.

The city of Firenze lies on the Arno River fluvial deposits (mostly sands and gravel) overlying a thin (shale and lime) lacustrine sequence [15]. The basement of the basin is intersected by transverse faults, causing a variable sediments thickness spanning from few hundreds of meters, mostly west of the city, to few tens of meters (typically $<60 \mathrm{~m}$ ) below downtown Firenze [16]. Seismic amplification effects in the basin have been documented since long time, based both on instrumental seismic analyses [17] as well as observations of produced damages [18]. Recently Coli et al. [16] provided a map of the seismic amplification for Firenze based on 1D modeling and confirmed by instrumental measurements.

The authors reconstructed the 3D velocity model for the sediments below the city of Firenze by exporting information from down-hole seismic surveys reaching the bedrock to the sedimentary information available from more than 10000 drill holes all around 
the city [16]. Here, 1D modeling of S wave propagation from the bedrock to the surface was performed by using SHAKE91 [19] and the final amplification factor was evaluated. The resulting map was confirmed with instrumental measurements of earthquakes with variable magnitude, epicentral distance $(<400 \mathrm{~km})$ and azimuth by using a reference station positioned on bedrock just outside the city and free from site effects and simultaneous seismic measurements within the city, performed on soft deposits. By combining the peak ground acceleration expected in Firenze $(0.15 \mathrm{~g})$ and the amplification factor estimated for the Galleria dell' Accademia Museum (about 1.7) [16], where the David statue has been exhibited since 1873, a maximum peak ground acceleration of $\sim 0.25 \mathrm{~g}$ can be estimated. Hence, the acceleration we assume was produced at Glendale by the Northridge earthquake is similar to the maximum value expected in Firenze every 500 years and amplified by local site effects.

\section{The Michelangelo's David and the replica: Marble characteristics}

To compare the behavior of the original David and the Glendale replica during an earthquake, marble characteristics of the two statues were also analyzed. Accordingly to the information provided by one of the Authors (JY), the Glendale replica destroyed by the Northridge earthquake was realized from an Italian (Carrara quarries, Apuane Alps, northern Tuscany) marble block. The mineralogical (XRD) and textural features of a small fragment picked up from the Glendale statue basement reveals the presence of prevailing calcite with traces of quartz. The petro-graphical examination confirmed a crystalloblastic metamorphic lithotype composed of subhedral and euhedral calcitic crystals with mainly lobate/sutured grain boundaries and secondary straight boundaries. The microstructure varies from homeoblastic to heteroblastic, with grains having a size generally varying from 50 to $80 \mu \mathrm{m}$ with a smaller number from 100 to $150 \mu \mathrm{m}$ (Figure 2a). Occasionally, quartz was observed.

These mineralogical and petrographic characteristics are compatible to a generic compact, homogeneous microcrystalline variety of a white marble from Apuane Alps-Versilia territory (Tuscany, Italy) $[20,21]$. The rock of the replica is however different with respect to the marble of original Michelangelo's David. This last marble has an homeoblastic texture of grano blastic and polygonal type, sub-rectilinear contacts among the calcite crystals and size from 200 to $500 \mu \mathrm{m}$ (Figure 2b) [1]. It is known, indeed, that the original David's marble is a white marble coming from the Apuane Alps, specifically Fantiscritti quarry [1-3]. The compressive strength tests carried out on samples taken from the Glendale replica by Quan tech Systems point to a value of about $500 \mathrm{~kg}$ $\mathrm{cm}^{2}$, that is, about a half of the average strength of the Carrara marble [22]. Although this is comforting, it has to be considered that the mechanical properties of the original David marble are compromised by the fracture network occurring at the statue's ankles [13], that represent a critical point for the statue stability. As recently reported by Pascale and Lolli [5] the most important cracks affecting the ankles of the David statue, measured using an ultrasonic investigation, may reach depths of about $20 \mathrm{~mm}$. The right leg is indeed characterized by the presence of a widespread micro-cracked volume.

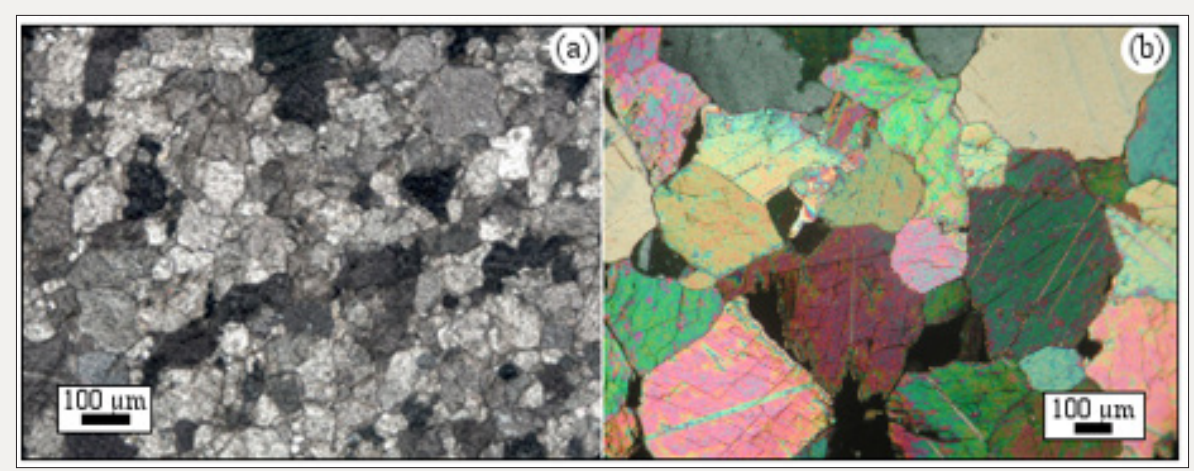

Figure 2b: Photographs in transmitted light microscopy (crossed nicols) showing the main petrographic features of marbles from David's copy in Glendale.

Figure 2b: The original David in Firenze.

\section{Conclusion}

In 1994, the Northridge seismic event occurred in 1994 at Glendale (USA) was responsible for the collapse of a marble full size replica of the Michelangelo David hold in the Forest Lawn Memorial Park. In the present study, we determined that the peak ground acceleration of $\sim 0.25 \mathrm{~g}$ - the same experienced at Glendale has a recurrence time of 475 years at the Galleria dell' Accademia Museum, where the Michelangelo David statue has been exhibited since 1873. However, the different petro-graphical and mechanical properties of the two marbles, constituting respectively the true David and the replica, indicated that comparison is not straight ford.
Although the David did not suffer any apparent effect from the 1895 (worst?) earthquake in Firenze, we cannot safely conclude that it is free from a possible seismic risk. We suggest a protection against earthquakes worthwhile in order to admire the Michelangelo's David standing for the next 500 years. As a concluding remark, we add a new possible explanation on the origins of the hairline cracks affecting the David ankles: why not caused by the past earthquakes?

\section{Acknowledgement}

This work was supported by the university ordinary funds of research appointed to Prof. Pilario Costagliola. Dr. Emma Cantisani (CNR-ICVBC Firenze) is gratefully thanked for her help regarding 
the study of marbles. In addition we would like to thank Prof. Piero Lattanzi (CNR-IGG Firenze) for useful suggestions to the paper.

\section{References}

1. Bracci S, Falletti F, Matteini M, Scopigno R (2004) Exploring David: Diagnostic tests and state of conservation (Giunti Editore, Firenze).

2. Anderson S (2016) David's ankles: How imperfections could bring down the world's most perfect statue. The New York time magazine, USA.

3. Corti G, Costagliola P, Bonini M, Benvenuti M, Pecchioni E, et al. (2014) Modelling the failure mechanisms of Michelangelo's David through small-scale centrifuge experiments. J Cult Herit 16(1): 26-31.

4. Pieraccini M, Betti M, Forcellini D, Dei D, Papi F, et al. (2017) Radar detection of pedestrian-induced vibrations on Michelangelo's David. PLoS ONE 12: e0174480.

5. Pascale G, Lolli A (2015) Crack assessment in marble sculptures using ultrasonic measurements: Laboratory tests and application on the statue of David by Michelangelo. J Cult Herit 16(6): 813-821.

6. Borri A, Grazini A (2006) Diagnostic analysis of the lesions and stability of Michelangelo's David. J Cult Herit 7(4): 273-285.

7. Quantic Systems (1994) Reassembly of statue of David for Forest Lawn Memorial Park, Report of Quantech Systems.

8. Porcella RL, Etheredge EC, Maley RP, Acosta A V (1994) Accelerograms recorded at USGS National strong-motion network stations during the Ms=6.6 Northridge, California earthquake of January 17, 1994 Department of the Interior Geological Survey, USA, pp. 94-141.

9. Dewey JW, Reagor BG, Dengler L, Moley K (1995) Intensity distribution and isoseismal maps for the Northridge, California, earthquake of January 17, 1994. U.S. Geological Survey, pp. 95-92.

10. Todd DR, Carino NJ, Chung RM, Lew HS, Taylor AW, et al. (1994) Northridge Earthquake: Performance of Structures, lifelines and fire protection systems. NIST, p. 5396.

11. A Rovida, M Locati, R Camassi, B Lolli P Gasperini (2015) Istituto Nazionale di Geofisica e Vulcanologia 2015 CPTI15, the 2015 version of the Parametric Catalogue of Italian Earthquakes.
12. Stucchi M, Meletti C, Montaldo V, Crowley H, Calvi GM, et al. (2011) Seismic hazard assessment (2003-2009) for the Italian building code Bull. Seismol Soc Am 101(4): 1885-1911.

13. Meletti C, Galadini F, Valensise G, Stucchi M, Basili R, et al. (2008) A seismic source zone model for the seismic hazard assessment of the Italian territory. Tectonophysics 450(1-4): 85-108.

14. Sabetta F, Pugliese A (1987) Attenuation of peak horizontal acceleration and velocity from Italian strong-motion records Bull. Seismol Soc Am 77: 1491-1513.

15. Pallecchi P, Benvenuti M, Cianferoni C (2010) The water in the development of Florence (Central Italy) between the Roman and the Renaissance ages: the resource and the hazard. J Quat Sci 23(2bis): 323334.

16. Coli M, Dinoi G, Lacanna G, Marchetti E, Pini G, et al. (2008) Firenze, Carta sismica del territorio comunale (SELCA, Firenze).

17. D’Amico V, Picozzi M, Baliva F, Albarello D (2008) Ambient noise measurements for preliminary site-effects characterization in the urban area of Florence, Italy Bull. Seismol Soc Am 98: 1373-1388.

18. Guidoboni E, Ferrari G (1995) Historical cities and earthquakes: Florence during the last nine centuries and evaluation of seismic hazard. Ann Geophys 38(5-6): 617-647.

19. Idriss IM, Sun JI (1993) User's manual for SHAKE91: A computer program for conducting equivalent linear seismic response analyses of horizontally layered soil deposits.

20. Cantisani E, Fratini F, Malesani P, Molli G (2005) Mineralogical and petrophysical characterisation of white Apuan marble Period. Mineral 74(2): 117-140.

21. Cantisani E, Pecchioni E, Fratini F, Garzonio CA, Malesani P, et al (2009) Thermal stress in the Apuane Marble: Relationship between microstructure and petrophysical characteristics. Int J Rock Mech Min Sci 46(1): 128-137.

22. Garzonio CA, Cantisani E (2006) Mechanical decay and degradation of marble slabs. Eurock: Multiphysics, pp. 461-466.
Creative Commons Attribution 4.0 International License

For possible submissions Click Here

\section{Submit Article}

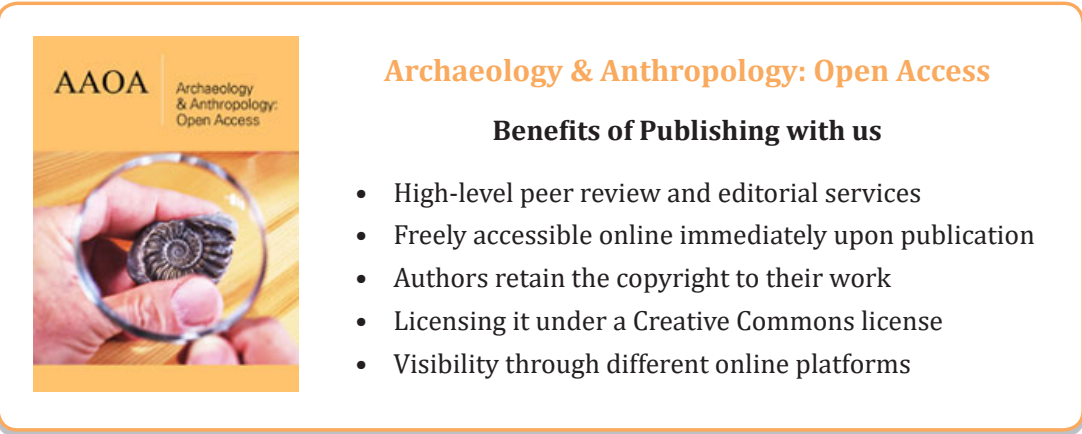

